\section{(2) OPEN ACCESS}

\title{
Adverse social behaviour at the workplace and subsequent physician certified sick leave: a three- wave prospective study of the general working population in Norway
}

\author{
Tom Sterud 도 , Eirik Degerud, Øivind Skare, Therese N Hanvold, Jan Olav Christensen
}

National Institute of Occupational Health (STAMI), Oslo, Norway

\section{Correspondence to} Dr Tom Sterud, National Institute of Occupational Health (STAMI), PO box 5330 Majorstuen, 0304 Oslo, Norway; tom.sterud@stami.no

Received 9 August 2020 Revised 23 December 2020 Accepted 30 December 2020 Published Online First 29 January 2021
Check for updates

(c) Author(s) (or their employer(s)) 2021. Re-use permitted under CC BY-NC. No commercial re-use. See rights and permissions. Published by BMJ.

To cite: Sterud T,

Degerud E, Skare Ø,

et al. Occup Environ Med

2021:78:576-582.

\section{ABSTRACT}

Objectives We aimed to provide an integrated picture of the relationship between different facets of adverse social behaviour (ASB) at the workplace and sick leave. Methods Data from a randomly drawn prospective cohort of the general working population. Eligible respondents were interviewed in 2009, 2013 or 2016 , and were registered with an employee relationship of at least 50 working days in the national register the year following the survey interviews ( $n=21674$ observations/13470 respondents). We investigated the prospective associations of self-reported exposure to $A S B$, including threats/acts of violence, bullying and sexual harassment, with physician-certified sick leave of 1-16 days (ie, low level of sick leave (LLSL)) and $>16$ days (ie, high level of sick leave (HLSL)) by means of mixed effects logistic regression.

Results The prevalence of sick leave was $18.4 \%$ ( $n=3986$ observations) for LLSL and 16.1\% ( $n=3492$ observations) for HLSL. The different facets of ASB were independently associated with higher odds of sick leave, with stronger associations for HLSL than for LLSL. Adjusted for sex, age, education level, occupation, previous sickness absence level, OR $(95 \% \mathrm{CI})$ for HLSL was 1.97 (1.61 to 2.35) for threats/acts of violence, 1.97 (1.53 to 2.54) for bullying and 1.41 (1.10 to 1.79) for sexual harassment. The population risks of LLSL and HLSL attributable to ASB were $5.27(95 \% \mathrm{Cl} 1.85$ to 8.81$)$ and $8.27 \%(95 \% \mathrm{Cl} 4.01$ to 12.48$)$, respectively.

Conclusions Threats/acts of violence, bullying and sexual harassment were all independent predictors of sick leave, with threats/acts of violence appearing as the single most important factor.

Sick leave is absence from work due to impaired functioning caused by health problems. Exposures in the workplace, work content and work environment can contribute to the development of health problems and impaired work ability, and thereby influence both the occurrence and the duration of sick leave. ${ }^{1}$ Previous research on the relationship between potentially stressful work characteristics and sick leave has mainly been conducted within the theoretical framework of the Job demandcontrol model. ${ }^{2-4}$ The labour market shift towards the service industry implies that the relative significance of social stressors will increase with a surge of social interactions with patients, customers,

\section{Key messages}

What is already known about this subject?

- There is good evidence that general job stressors are associated with sick leave. Less attention has been devoted to the likely negative consequences of adverse social behaviour (ASB) at the workplace.

What are the new findings?

- Threats/acts of violence, bullying and sexual harassment are independent risk factors for physician certified sick leave in the Norwegian general workforce.

- Collectively, ASB accounted for $5 \%$ and $8 \%$ of the occurrences with low and high level of sick leave, respectively. Threats/acts of violence appeared as the single most important factor.

How might this impact on policy or clinical practice in the foreseeable future?

- The results of the present study indicate that organisations should raise efforts to prevent and handle ASB at the workplace.

clients or coworkers. Thus, the present study aimed to contribute to the literature by investigating the importance of different facets of adverse social behaviour (ASB) at the workplace as risk factors for physician certified sick leave in the general working population.

ASB in the workplace has been defined as any act of physical and verbal violence and intimidation at work, and includes threats/acts of violence, bullying, and sexual harassment. ${ }^{5}$ ASB can negatively affect the work environment and have detrimental effects on the mental health, productivity and absence behaviour of employees. ${ }^{6-8}$ Judging by the number of systematic literature reviews, bullying appears to be the most frequently studied facet of ASB in the workplace..$^{7-11}$ Bullying is a documented risk factor for sick leave in a substantial number of longitudinal studies. ${ }^{8}$ Studies addressing and threats/acts of violence and sexual harassment as risk factors for sick leave, however, are sparse. ${ }^{6}$ Non-fatal violence and threats have in some longitudinal studies been associated with increased risk of long-term sick leave in female 
health and social workers ${ }^{1516}$ and human service professionals, ${ }^{17}$ and a few general working population samples. ${ }^{18} 19$ Unwanted sexual attention from colleagues or managers was reported to predict long-term sick leave among men, but not women, ${ }^{20}$ and both men and women ${ }^{21}$ in studies of the general working population in Denmark, whereas a non-significant excess risk of sick leave associated with unwanted sexual attention was reported in a sample of female elder-care workers. ${ }^{16}$

As our summary of the literature shows, there is a limited number of prospective studies that have provided data on associations of threats/acts of violence and sexual harassment with register data on sick leave, ${ }^{15} 16182021$ and even fewer studies based on general working population samples. ${ }^{18} 2021$

Moreover, previous studies have mainly reported ASBs as risk factors for long-term sick leave, ${ }^{15161920}$ whereas the associations of ABS's with sick leaves of different lengths are inconclusive. ${ }^{22}$ In this study, we provide data on the prospective associations of different facets of ASB with register data on sick leave from a randomly drawn prospective cohort of the general working population in Norway. First, our study contributes to the literature by allowing us to examine and compare the strength of the relationships between acts/threats of violence, bullying and sexual harassment and physician certified sick leave of different duration across a wide range of occupations. Second, our study further contributes to the literature by simultaneously testing the association between different facets of ASB and sick leave, and estimating the population-attributable risk (PAR). The latter constitutes an important tool that indicate the importance of ASBs as risk factors for sick leave at the population level. We are aware of one general working population study that have addressed this question pertaining to threats/acts of violence. ${ }^{19}$

\section{METHODS}

\section{Study design and study population}

The current study obtained longitudinal data from the ongoing nationwide Survey of Level of Living-Working Conditions, conducted by Statistics Norway. In the present study, we used data that were collected between June 2009 and January 2010, April 2013 to January 2014 and September 2016 to April 2017, predominantly by personal telephone interview $(0.5 \%$ of the interviews were completed face to face).

The source population for the nationwide survey were Norwegian residents aged 18-66 years. In 2009, a gross sample of 20 136 was randomly drawn from this population. Of these, 12 255 persons were interviewed (response 60.9\%). The same gross sample were reinvited to participate in 2013 ( $n=10875$ interviews, response 53.1\%). In 2016, two-thirds of original gross sample were reinvited to participate. Due to a planned rotation of the panel selection, one-third of the sample was replaced by a new randomised subsample that was interviewed for the first time in 2016 ( $\mathrm{n}=10665$ interviews, response 52.6\%). To ensure the representativeness of each survey sample, Statistics Norway have supplemented the sample with 17 years, 18 years and 19 years and immigrants at each wave. For each survey year, the baseline sample was compared with the gross sample according to the benchmarks of age, sex and region. No major differences were observed. ${ }^{23}$ In each survey, respondents who confirmed that they were in paid work for at least 1 hour during the interview week, or were temporarily absent from such work, were interviewed about working conditions. Sick leave data were obtained from the Norwegian Labour and Welfare Administration's sickness benefit register. The register includes all workers aged 16-69 living in Norway registered with an employee relationship of at
Table 1 Description of the sample

\begin{tabular}{|c|c|c|c|c|c|}
\hline & \multicolumn{3}{|c|}{ Sample per survey } & \multicolumn{2}{|c|}{ Sample in total } \\
\hline & 2009 & 2013 & 2016 & Observations & Individuals \\
\hline Gross sample* & 20136 & 20492 & 20272 & $60900 *$ & \\
\hline Net sample† & 12255 & 10875 & 10665 & 33795 & 20341 \\
\hline Response percentage & 60.9 & 53.1 & 52.6 & 55.5 & \\
\hline Working population $\neq$ & 9279 & 8375 & 8329 & 25983 & $15866 \S$ \\
\hline $\begin{array}{l}\text { Active employee } \\
\text { relationship of at least } \\
50 \text { days }\end{array}$ & 7709 & 7077 & 7302 & 22088 & 13731 \\
\hline Eligible sample** & & & & 21671 & 13473 \\
\hline
\end{tabular}

*Randomly drawn population sample (*maximum number of possible observations).

Total number of respondent including employed and non-employed individuals.

‡Respondents who were in paid work for at least 1 hour during the interview week, or were temporarily absent from such work were

$\$$ Sum of individuals that were interviewed about working conditions in one survey $(n=8504)$, two surveys $(n=4607)$ and three surveys

१Registered with an active employee relationship of at least 50 actual working days in the survey year and the following year in the

"*Eligible sample after deletion of respondents with missing values ( $\mathrm{n}=258(1.9 \%)$ individuals).

least 4 hours per average working week in the reference period. The registry does not include self-employed workers.

Eligible respondents were interviewed about working conditions in 2009, 2013 or 2016, and were registered with an employee relationship of at least 50 working days in the national register in the survey year and the following year $(n=22088$ observations nested in $n=13731$ individuals). We excluded respondents that were self-employed with no employees, respondents with missing values on either of the exposure variables or with missing values on education level or occupation in all three surveys $(n=258)$. See table 1 for a full description of the sample.

\section{Measurement of sick leave}

Data on sick leave were only available as the accumulated number of physician-certified sick leave days during a calendar year (ie, 2010, 2014 and 2017 constitute the follow-up period for each of the surveys), irrespective of the individual's date of responding to the questionnaire. Due to skewness and clustering around zero, the variable was recoded into three categories: ' 0 days', '1-16 days' (low level of sick leave, (LLSL)) and '>16 days' (high level of sick leave (HLSL)). The cut-off (16 days) was chosen for two reasons: (1) it distinguishes between sickness absence days paid by the employer and sickness absence days paid by the Norwegian Labour and Welfare Administration, and (2) it was close to the median number of sick leave days among respondents with sick leave (ie, 15 days). In Norway, employees receive full compensation from the first day with sick leave. Employees have the right to self-certification for three sick leave periods of up to 3 days, and some up to eight consecutive days. If a single period of absence exceeds the specified number of days (ie, 3 or 8 days), a physician's certificate is required.

\section{Measurement of ASBs}

The items covering the different facets of ASBs were originally developed by an Nordic expert group, ${ }^{24}$ and have later been slightly modified. Effects of ASBs on mental distress has been reported in a sister paper. ${ }^{25}$ Threats/acts of violence was measured with three items: 'Over the past 12 months have you (Q1) been the victim of violence at the workplace that caused visible marks or physical damage? (Q2) been the victim of violence at the workplace that did not cause visible marks? (Q3) been threatened at the workplace in such a way that you felt scared?' Answer categories were 'yes' and 'no'. The items were computed into one dichotomous variable (yes at any item $=1$, no $=0)$. 
Bullying was measured with two questions: 'Do you sometimes: (Q1) get bothered or teased in an unpleasant way by your colleagues? (Q2) get bothered or teased in an unpleasant way by superiors?' (Answer categories: yes, $\geq 1$ a week; yes, $\geq 1$ a month; no) Bullying was dichotomised into exposed for the ones who answered 'yes' on any of the two questions. This definition of bullying has shown good convergent validity with a single item measure of bullying (including a definition of bullying as repeated negative acts within a 6-month period) used in another validated questionnaire. ${ }^{2627}$

Sexual harassment was measured with a single item: 'Do you sometimes: (Q1) receive unwanted sexual attention, comments at your workplace? (Answer categories: yes, $\geq 1$ a week; yes, $\geq 1$ a month; no) Sexual harassment was dichotomised and those answering 'yes' were the exposed. Supplementary questions concerning perpetrators of sexual harassment were only available for the 2016 survey and were analysed in supplementary analyses (SQ1: Was this unwanted sexual conduct carried out by (1) a superior at the workplace (2) a colleague at the workplace or (3) a customer, client, pupil or someone else who is not an employee at your workplace?).

\section{Measurement of covariates}

Sex, age, education level, the number of actual working days and baseline sick leave were based on administrative registry data. Age and education were treated as continuous variables in the regression analyses, but were recoded into dummy variables for descriptive purposes (table 2). Occupation was based on an open questionnaire and coded by Statistics Norway into professional title in accordance with the International Standard Classification of Occupations (ISCO-08). ${ }^{28}$ We combined one-digit and twodigit codes and recoded into 17 occupational groups to obtain sufficiently large groups to present data (see table 2). For supplementary analyses, we merged occupation with frequent client contact, including health and teaching professionals, service and sales workers (ISCO codes: 22-23, 32, 42, 51-54), and other occupations with less frequent client contact.

\section{Statistical analyses}

The distribution of exposure to ASBs and sick leave by covariates was described and tested for differences by means of $\chi^{2}$ tests. To assess the association between each facet of ASB and the risk of sick leave in the following year, we applied generalised linear mixed models (GLMM). More, specifically, mixed effects logistic

Table 2 Prevalence of adverse social behaviour and sick leave by sex, age, education and occupation

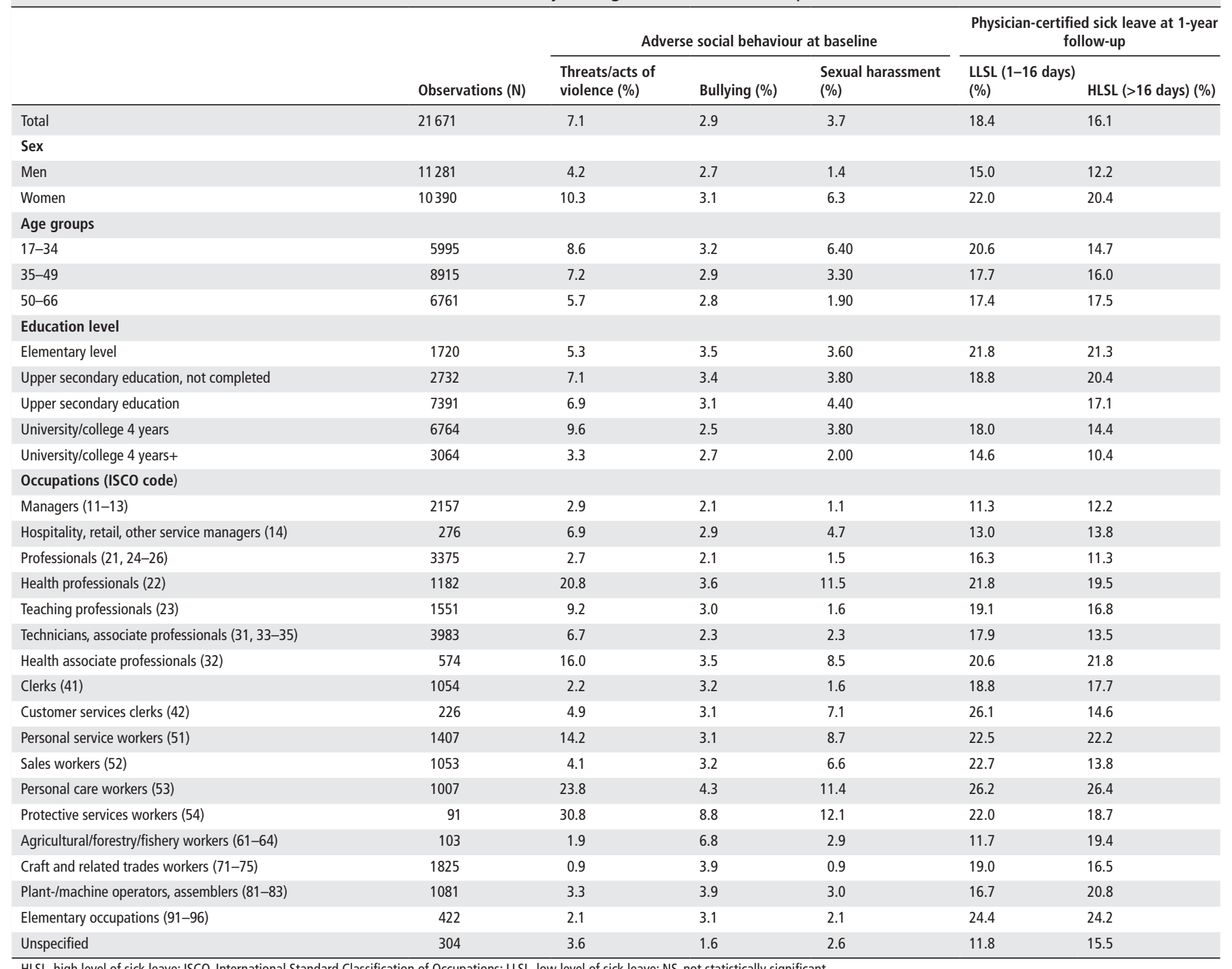

HLSL, high level of sick leave; ISCO, International Standard Classification of Occupations; LLSL, low level of sick leave; NS, not statistically significant. 
regression was our preferred method as it is appropriate when analysing non-normal outcome variables that that are clustered within units (in the current case repeated observations from the same individuals), and when the follow-up time does not vary between individuals (the follow-up period was set to 1 year for all individuals since information regarding precise start and stop dates for a given period of sick leave was not available). Moreover, GLMMs use all available data by computing maximum likelihood estimates based on valid data from at least one time point. All analyses were carried out using the statistical software R V.3.6.1. We used the glmer command of the package lme4 to compute mixed effects logistic regressions (ie, logistic link function). Estimates were based on an adaptive Gaussian Hermite approximation of the likelihood with 10 integration points.

Too address the issue of possible selection bias related to missing values and attrition, we tested (1) if missing values on any exposure variable predicted sick leave at follow-up and (2) if response at follow-up was dependent on exposure, outcome and confounder variables at baseline.

The prospective associations between each ASB and sick leave were reported as ORs with 95\% CIs. We set a significance level of 0.05 . First, we computed four time-lagged regression models (A, B, C and D) with sick leave regressed on the ASB measured the previous year. All models included random intercepts to control for non-independence of measurements within individuals (ie, taking into account the individual's general level of sick leave across time). Model A was adjusted for sex, age and number of actual working days, whereas further adjustments for occupation and educational level were carried out in model B. In model $\mathrm{C}$, we adjusted for baseline sick leave to take account of reverse associations, and examined the associations between each facet of ASB and sick leave independently (research aim 1). In model $\mathrm{D}$, we tested all exposure variables simultaneously to obtain mutually adjusted OR's to calculate the population attributable risk percent (PAR \%) of ASBs (research aim 2). The interpretations of PAR estimates are based on the theoretical assumption that the exposure-response relationship is causal, and was calculated using the formula Pd*((OR-1)/OR), where Pd is the proportion of cases exposed to the risk factor in question. The lower and upper limits of the 95\% CI for PAR\% were calculated from the general PAR\% formula using the lower and upper limits of the $97.5 \% \mathrm{CI}$ for Pd and OR. ${ }^{29}$ Summary attributable risk was calculated according to the formulae: 1 (1 PAR $\left._{\text {var1 }}\right)$ $\left.\left(1 \operatorname{PAR}_{\text {var } 2}\right)\left(1 \quad \operatorname{PAR}_{\text {var } 3}\right)\right)^{30}$

In supplementary analyses, we conducted interaction analyses on a multiplicative scale (ie, model fit for models with and without a two-way interaction term were compared using the likelihood ratio test) to evaluate whether the strength of the associations were modified by sex and occupation. Furthermore, in exploratory analyses we evaluated the associations for threats and violence separately, and the separate associations for unwanted sexual attention from (1) coworkers/leaders and (2) clients/customer, respectively.

\section{RESULTS}

\section{Attrition analyses}

Among respondents that fulfilled the inclusion criteria at baseline, $3.6 \%$ of the respondents $(n=800)$ did not fulfil the inclusion criteria at follow-up (ie, registered with $<50$ actual working days in the sickness benefit register). Attrition was associated with sexual harassment (OR 2.05 95\% CI 1.50 to 2.80) and HLSL (OR $2.4195 \%$ CI 1.96 to 2.96). A non-significant increased odds of attrition was observed for bullying (OR 1.37 95\% CI
Table 3 Mixed effects logistic regression: sick leave at 1-year followup regressed on work-related adverse social behaviour measured at baseline

\begin{tabular}{|c|c|c|c|c|}
\hline & \multicolumn{2}{|c|}{$\begin{array}{l}\text { LLSL }(1-16 \text { days }) \\
\left(n^{*}=18179 / \text { cases } t=3986\right)\end{array}$} & \multicolumn{2}{|c|}{$\begin{array}{l}\text { HLSL ( }>16 \text { days }) \\
(n \neq=17685 / \text { cases } t=3492)\end{array}$} \\
\hline & OR§ & $95 \% \mathrm{Cl}$ & OR§ & $95 \% \mathrm{Cl}$ \\
\hline Threats/acts of violence 9 & 1.80 & (1.53 to 2.11 ) & 2.66 & (2.19 to 3.23 ) \\
\hline Threats/acts of violence ** & 1.66 & (1.41 to 1.95$)$ & 2.38 & (1.96 to 2.89$)$ \\
\hline Threats/acts of violence $\dagger \dagger$ & 1.62 & (1.38 to 1.90$)$ & 1.97 & (1.61 to 2.35$)$ \\
\hline Threats/acts of violence $\ddagger \ddagger$ & 1.56 & (1.32 to 1.84$)$ & 1.87 & (1.57 to 2.24 ) \\
\hline Bullyingी & 1.70 & (1.33 to 2.17 ) & 2.60 & (1.96 to 3.46$)$ \\
\hline Bullying** & 1.61 & (1.27 to 2.05 ) & 2.39 & (1.81 to 3.16$)$ \\
\hline Bullyingt† & 1.52 & (1.21 to 1.97$)$ & 1.97 & (1.53 to 2.54$)$ \\
\hline Bullying $\neq \ddagger$ & 1.42 & (1.12 to 1.81$)$ & 1.82 & (1.41 to 2.35$)$ \\
\hline Sexual harassment & 1.55 & (1.25 to 1.92$)$ & 2.11 & (1.62 to 2.76$)$ \\
\hline Sexual harassment ${ }^{\star *}$ & 1.39 & (1.13 to 1.72$)$ & 1.77 & (1.36 to 2.30$)$ \\
\hline Sexual harassment $\dagger$ & 1.35 & (1.09 to 1.67 ) & 1.41 & (1.10 to 1.79$)$ \\
\hline Sexual harassment $\ddagger \ddagger$ & 1.18 & (0.95 to 1.47 ) & 1.16 & (0.91 to 1.48 ) \\
\hline
\end{tabular}

Reference value=not exposed (not shown).

*Net sample excluding cases (observations) of HLSL from the denominator.

tNumber of sick leave observations during follow-up.

¥Net sample excluding cases (observations) with LLSL from the denominator.

$\S$ Fixed effects from the random effects logistic regression models.

IAdjustment for sex, age and number of actual working days (continuous) +random intercept.

$* *+0$ ccupation and education level (continuous).

$\dagger++$ Sick leave days the year of the survey interview.

$\ddagger \neq+$ All facets of ASB tested simultaneously.

ASB, adverse social behaviour; HLSL, high level of sick leave; LLSL, low level of sick leave

0.91 to 2.05 ) and threats/acts of violence (OR 1.21 95\% CI 0.91 to 1.60 ), but not LLSL (OR $0.9495 \%$ CI 0.75 to 1.19). Attrition was higher for women, the lowest (17-34) and highest (50-66) age groups, and for respondents with lower education levels. Among respondents that fulfilled the inclusion criteria at both baseline and follow-up, respondents with missing values did not have a significant higher level of sick leave compared with the sample included in the analyses (analyses not shown).

\section{Sample characteristics}

In total, 21671 observations and 13473 respondents were included in the statistical analyses (see table 1 for a full sample description). The prevalence of sick leave was 18.4\% ( $n=3986$ observations) for LLSL and 16.1\% ( $n=3492$ observations) for HLSL. Table 2 further shows that sick leave was associated with being a woman, younger age, lower education levels and occupation $(p<0.05)$. The prevalence of ASB was $7.1 \%$ for threats/ acts of violence, $2.9 \%$ for bullying and $3.7 \%$ for sexual harassment. The pairwise spearman correlations for the dichotomous exposure variables were $\rho=0.12$ (bullying-sexual harassment), $\rho=0.07$ (bullying-violence) and $\rho=0.21$ (sexual harassmentviolence.) Threats/acts of violence and sexual harassment were more prevalent among women and the youngest workers $(\mathrm{p}<0.05)$, whereas bullying was not related to age or sex. All facets of ASB were correlated with occupation and education level $(p<0.05)$.

\section{Main analyses}

Table 3 shows OR with 95\% CI for sick leave according to each ASB. In the crude model A for LLSL, the associations ranged from $O R=1.55$ (sexual harassment) to $\mathrm{OR}=1.80$ (threats/acts of violence). Adjusting for occupation and education level in model $\mathrm{B}$ reduced the OR's (range 5\%-10\% reduction), and ORs were further reduced (range 3\%-6\% reduction) when adjusted for baseline sick leave (model C). Threats/acts of violence, bullying and sexual harassment were associated with 1.62-fold $(95 \% \mathrm{CI}$ 
Table 4 Calculated population attributable risk percentage (PAR\%) based on ORs from model\#D in table 3

\begin{tabular}{|c|c|c|c|c|}
\hline & \multicolumn{2}{|c|}{$\begin{array}{l}\text { LLSL (1-16 days) } \\
\left(n^{*}=18179 /\right. \\
\text { occurrences } t=3986)\end{array}$} & \multicolumn{2}{|c|}{$\begin{array}{l}\text { HLSL (>16 days) } \\
(n \neq=17685 / \\
\text { occurrences } t=3492)\end{array}$} \\
\hline & PAR (\%) & $95 \% \mathrm{Cl}$ & PAR (\%) & $95 \% \mathrm{Cl}$ \\
\hline $\begin{array}{l}\text { Threats/acts of } \\
\text { violence§ }\end{array}$ & 3.48 & $\begin{array}{l}(1.96 \text { to to } \\
5.02)\end{array}$ & 5.48 & (3.65 to 7.33 ) \\
\hline Bullying§ & 1.09 & (0.24 to 2.01 ) & 2.18 & (1.07 to 3.33 ) \\
\hline $\begin{array}{l}\text { Sexual } \\
\text { harassment§ }\end{array}$ & 0.78 & $(-0.36$ to 2.02$)$ & 0.79 & $(-0.70$ to 2.30$)$ \\
\hline Sum & 5.27 & (1.85 to 8.81$)$ & 8.27 & (4.01 to 12.48 ) \\
\hline
\end{tabular}

${ }^{*}$ Net sample excluding occurrences of HLSL.

tNumber of sick leave occurrences during follow-up.

¥Net sample excluding occurrences of LLSL.

$\S$ Adjusted for sex, age, occupation, education level, the number of actual working days and sick leave days the year of the survey year and other facets of ASB.

ASB, adverse social behaviour; HLSL, high level of sick leave; LLSL, low level of sick leave; N/A, not applicable.

1.38 to 1.90 ), 1.52 -fold (95\% CI 1.21 to 1.97 ) and 1.35 -fold (95\% CI: 1.09 to 1.47 ) increase of odds, respectively, based on model C. Finally, in model D, ORs were further reduced by $4 \%-12 \%$ when all measures of ASB were tested simultaneously.

In the crude model A for HLSL, the associations ranged from $\mathrm{OR}=2.11$ (sexual harassment) to $\mathrm{OR}=2.66$ (threats/acts of violence). Adjusting for occupation and education in model $\mathrm{B}$ reduced the OR's (range 8\%-16\% reduction), and the ORs were further reduced (range 17\% $\%-21 \%$ reduction) when adjusted for baseline sick leave (model C). Threats/acts of violence, bullying and sexual harassment were associated with 1.97 -fold $(95 \% \mathrm{CI}$ 1.61 to 2.35 ), 1.97 -fold (95\% CI 1.53 to 2.54 ) and 1.41 -fold (95\% CI 1.10 to 1.79 ) increase of odds, respectively, based on model C. Finally, in model D, ORs were further reduced by $5 \%-18 \%$ when all measures of ASB were tested simultaneously.

Table 4 shows the estimated PAR\% of sick leave due to each ASBs individually and to the ASBs collectively, which was calculated by using the fully adjusted ORs shown in table 3 (model D). The proportion of LLSL attributed to ASB collectively was $5.27 \%$ 95\% CI 1.85 to 8.81 . In the model for HLSL the proportion of sick leave attributed to ASB collectively was: $8.27 \%$ 95\% CI 4.01 to $12.48 \%$. The largest PAR estimate was observed for threats/acts of violence (3.48 95\% CI 1.96 to 5.02 (LLSL) and $5.4895 \%$ CI 3.65 to 7.33 (HLSL)).

\section{Supplementary analyses}

In age-adjusted models for LLSL and HLSL, the interaction analyses indicated a stronger association between bullying and LLSL among men than women (OR 2.21 95\% CI 1.57 to 3.12 vs OR $1.3395 \%$ CI 0.95 to 1.88 , respectively, $\mathrm{p}<0.05$ ), and a similar pattern was also observed for HLSL (OR 3.30 95\% CI 2.12 to 5.14 vs OR $2.1595 \%$ CI 1.49 to 3.11 , respectively, $\mathrm{p}=0.21$ ). Associations between threats/acts of violence and sexual harassment and sick leave were similar for men and women. Similarly, the strength of the relationships between ASBs and sick leave did not vary systematically according to occupation (ie, frequent client contact occupations vs non-frequent client contact occupations), and the interaction terms were not close to being statistically significant. Furthermore, in exploratory analyses (age-adjusted and sex-adjusted models), associations were similar for threats and for violence when evaluated separately. OR for LLSL was: $1.2995 \%$ CI 0.93 to 1.78 for threats vs 1.39 95\% CI 1.04 to 1.85 for violence and OR for HLSL was: 1.86
95\% CI 1.39 to 2.48 for threats vs $2.1395 \%$ CI 1.70 to 2.66 for violence. ORs for physician certified sick leave (no sick leave vs any sick leave) were also similar for sexual harassment from co-worker/leader (OR 1.40, 95\% CI 0.88 to 2.22) and client/ customers OR 1.71, 95\% CI 1.31 to 2.24 ) (analyses not shown).

\section{DISCUSSION}

This study investigated the role of different facets of ASB at the workplace as risk factors for physician certified sick leave in the Norwegian workforce. Both exposure to ASB and risk of sick leave were related to sex, age, education level and occupation. After adjusting for these variables and baseline sick leave, we observed time-lagged associations between threats/acts of violence, bullying and sexual harassment and sick leave. The associations were stronger for HLSL than for LLSL, and more robust for threats/acts of violence and bullying than for sexual harassment. The magnitude of the risk estimates was small to moderate, but given that these types of exposures are rather prevalent, the total impact on sick leave in the general working population is of importance.

Among the strengths of this study are the large, nationwide random sample with an acceptable response rate, the prospective design and the utilisation of different types of measurement for exposure (ie, self-report) and outcome (registry-based sick leave). The non-response examination by Statistics Norway showed minor differences between non-responders and responders across the benchmarks of age, sex and geographical region, whereas non-response was higher among respondents with elementary education level. ${ }^{23}$ The mixed-model analyses are also partly robust to attrition, it gives unbiased results when the missingness is not completely random, but can be fully accounted for by variables in the model. Nevertheless, the present attrition analyses showed that HLSL and sexual harassment were associated with lower probability of participation at follow-up. This may have contributed to an attenuation of the association between sexual harassment and HLSL.

Sick leave was measured as the accumulated number of days during a calendar year, because precise start and stop dates for a given period of sick leave were not available. Thus, theoretically it is possible that several sick leave periods add up to our definition of HLSL. However, since employees have the right to self-certification for three sick leave periods of up to 3 or 8 consecutive days, it is less likely that very many employees with HLSL have several short-term spells. Moreover, all exposure data were collected by self-report, and it cannot be ruled out that some unmeasured state or trait influencing exposure and sick leave may have inflated the estimates. To reduce the risk of reporting bias, and reverse causation ${ }^{8}$ due to sickness absence prior to the survey, we adjusted for sick leave days the year of the survey year. However, although baseline adjustment may reduce these biases, it may introduce others $\left(\mathrm{eg},{ }^{31}\right)$, and may lead to over adjustment if baseline differences reflect effect of previous exposure to ASB. ${ }^{32}$ Hence, we also present models without baseline adjustment for the outcome. Furthermore, the use of telephone interviews in this study could lead to an underestimation of exposure, because respondents may be apprehensive about the judgements of the interviewer when it comes to socially stigmatised actions such as bullying. ${ }^{33}$ Finally, although our exposure measures were developed by an Nordic expert group, ${ }^{24}$ their construct validity has not been extensively tested.

Our finding of a prospective association between exposure to threats/acts of violence and sick leave is an important contribution to the current literature on the topic. Previous studies have been 
mostly limited to health and social workers. ${ }^{15-17}$ The exception is a 10-year follow-up study of the Danish working population, ${ }^{18}$ which reported that exposure to violence was associated with a 1.7 times higher odds of health-related absence. Despite differences in study design, we found reasonably coincident estimates in our 1-year study of the Norwegian working population; a 1.6 times higher odds of LLSL and a twofold higher odds of HLSL. In the present study, threats/acts of violence were clearly more prevalent among women and in occupations with high degree of client contact (ie, health professionals, personal service workers, personal care workers and protective services workers), but the strength of the association between threats/acts of violence and sick leave was independent of sex and occupation.

The observed prospective association between bullying and sick leave of different durations, seem well established in the literature. ${ }^{8}$ The present results are based on a large number of observations, and adds to the literature by demonstrating a robust association after adjustment for rather detailed occupational information, and simultaneous adjustment for both sexual harassment and threats/acts of violence. For both LLSL and HLSL associations with bullying were stronger among men than women. This finding has some support in the literature, ${ }^{34}$ but needs to be confirmed in further population studies. It could indicate that bullying reported by men is of a more severe character, or that the men are more susceptible to the detrimental effects of bullying in comparison with women.

Sexual harassment was independently associated with LLSL and HLSL, but the associations were attenuated in the model adjusted for the other ASBs. We are aware of only two studies that have reported an association between sexual harassment and sick leave in general working population studies. Nabe-Nielsen et $a l^{21}$ reported a significant association between unwanted sexual attention and sick leave, but did not adjust for occupation or other potential confounders in the working environment. Hogh et $a l^{20}$ reported a statistically significant association between unwanted sexual attention from coworkers and increased risk of sick leave among men, but not among women. Moreover, after adjusting for job demands and job control the association with sexual harassment from clients was no longer significant. In supplementary analyses, we found that the association between sexual harassment from (1) colleagues or leader or (2) customers of clients and physician certified sick leave the following year, was similar.

Finally, we estimated the proportion of sick leave attributable to workplace ASB at the population level. Collectively, ASB accounted for about five and eight percent of LLSL and HLSL, respectively. The largest estimated attributable risk was observed for threats/acts of violence $(3.5 \%$ and $5.5 \%$ for LLSL and HSLS, respectively). These numbers are similar to the proportion of total sick leave $(4 \%)$ reported in a Swedish general working population study, ${ }^{19}$ and in the lower range of the proportions reported (3\%-9\%) in studies among humane service workers. ${ }^{15} 1719$ However, several limitations have to be taken into account. First, the accuracy of the PAR depends on the completeness of the specified model. Despite a thorough control of confounding factors in the fully adjusted model, we cannot rule out residual confounding. Moreover, because some individuals may simultaneously be exposed to more than one ASB, the combined PAR estimate may be somewhat overestimated. Second, the PAR estimates are based on the assumption that the exposure-response relationship is causal. Even though the inference of a possible causal relationship between ASB and sick leave is supported by the results from the presents study, the available data to support this inference is still limited.
In conclusion, in a nationwide study of the general working population, we found that threats/acts of violence, bullying and sexual harassment were all independent predictors of sick leave, with threats/acts of violence appearing as the single most important factor.

Contributors The article was conceived by TS, who also conducted analysis. ED, $\varnothing \mathrm{S}, \mathrm{TNH}$ and JOC contributed to analytic design, and to the interpretation of results. TS drafted the manuscript with feedback from all authors. All authors contributed to the final draft of the manuscript.

Funding The authors have not declared a specific grant for this research from any funding agency in the public, commercial or not-for-profit sectors.

Competing interests None declared.

Patient consent for publication Not required.

Ethics approval The survey was carried out by Statistics Norway according to statutory rules. Statistics Norway has appointed its own privacy ombudsman, approved by the Norwegian Data Inspectorate.

Provenance and peer review Not commissioned; externally peer reviewed.

Data availability statement Data may be obtained from a third party and are not publicly available. Statistics Norway has an established policy for data sharing. Requests for data (ie, The Norwegian Survey on Living conditions survey-working conditions) can be addressed to the Norwegian Centre for Research Data (https:// nsd.no/) or Statistics Norway (mikrodata@ssb.no)

Open access This is an open access article distributed in accordance with the Creative Commons Attribution Non Commercial (CC BY-NC 4.0) license, which permits others to distribute, remix, adapt, build upon this work non-commercially, and license their derivative works on different terms, provided the original work is properly cited, appropriate credit is given, any changes made indicated, and the use is non-commercial. See: http://creativecommons.org/licenses/by-nc/4.0/.

\section{ORCID iD}

Tom Sterud http://orcid.org/0000-0001-8393-8923

\section{REFERENCES}

1 Allebeck P, Mastekaasa A. Swedish Council on technology assessment in health care (SBU). Chapter 3. causes of sickness absence: research approaches and explanatory models. Scand J Public Health Supp/ 2004:63:36-43.

2 Allebeck P, Mastekaasa A. Chapter 5. Risk factors for sick leave - general studies. Scand J Public Health 2004:32:49-108.

3 Knardahl S, Sterud T, Nielsen MB. Arbeidsplassen OG sykefravær-Arbeidsforhold AV betydning for sykefravær. Tidsskrift for velferdsforskning 2016;19:179-99.

4 Duijts SFA, Kant I, Swaen GMH, et al. A meta-analysis of observational studies identifies predictors of sickness absence. J Clin Epidemio/ 2007:60:1105-15.

5 Eurofound. Violence and harassment in European workplaces: extent, impacts and policies. Dublin: Eurofound, 2015

6 Chan DK-S, Chow SY, Lam CB, et al. Examining the Job-Related, psychological, and physical outcomes of workplace sexual harassment: a meta-analytic review. Psychol Women Q 2008:32:362-76.

7 Samnani A-K, Singh P. 20 years of workplace bullying research: a review of the antecedents and consequences of bullying in the workplace. Aggress Violent Behav 2012;17:581-9.

8 Nielsen MB, Indregard A-MR, Øverland S. Workplace bullying and sickness absence: a systematic review and meta-analysis of the research literature. Scand I Work Environ Health 2016:42:359-70.

9 Verkuil B, Atasayi S, Molendijk ML. Workplace bullying and mental health: a metaanalysis on cross-sectional and longitudinal data. PLOS One 2015;10:e0135225.

10 Leach LS, Poyser C, Butterworth P. Workplace bullying and the association with suicidal ideation/thoughts and behaviour: a systematic review. Occup Environ Med 2017:74:72-9.

11 Branch S, Ramsay S, Barker M. Workplace bullying, Mobbing and general harassment: a review. Int J Manag Rev 2013;15:280-99.

$12 \operatorname{Hogh}$ A, Viitasara E. A systematic review of longitudinal studies of nonfatal workplace violence. Eur J Work Organ Psychol 2005;14:291-313.

13 Lanctôt N, Guay S. The aftermath of workplace violence among healthcare workers: a systematic literature review of the consequences. Aggress Violent Behav 2014;19:492-501

14 McDonald P. Workplace sexual harassment 30 years on: a review of the literature. Int $J$ Manag Rev 2012:14:1-17.

15 Aagestad C, Tyssen R, Johannessen HA, et al. Psychosocial and organizational risk factors for doctor-certified sick leave: a prospective study of female health and social workers in Norway. BMC Public Health 2014;14:1016. 
16 Clausen T, Hogh A, Borg V. Acts of offensive behaviour and risk of long-term sickness absence in the Danish elder-care services: a prospective analysis of register-based outcomes. Int Arch Occup Environ Health 2012;85:381-7.

17 Rugulies R, Christensen KB, Borritz M, et al. The contribution of the psychosocial work environment to sickness absence in human service workers: results of a 3-year followup study. Work Stress 2007;21:293-311.

18 Friis K, Larsen FB, Lasgaard M. Physical violence at work predicts health-related absence from the labor market: a 10-year population-based follow-up study. Psychol Violence 2018;8:484-94

19 Aronsson V, Toivanen S, Leineweber C, et al. Can a poor psychosocial work environment and insufficient organizational resources explain the higher risk of illhealth and sickness absence in human service occupations? Evidence from a Swedish national cohort. Scand J Public Health 2019;47:310-7.

20 Hogh A, Conway PM, Clausen T, et al. Unwanted sexual attention at work and long-term sickness absence: a follow-up register-based study. BMC Public Health 2016;16:678.

21 Nabe-Nielsen K, Grynderup MB, Lange T, et al. The role of poor sleep in the relation between workplace bullying/unwanted sexual attention and long-term sickness absence. Int Arch Occup Environ Health 2016:89:967-79.

22 Friis K, Pihl-Thingvad J, Larsen FB, et al. Long-term adverse health outcomes of physical workplace violence: a 7-year population-based follow-up study. Eur J Work Organ Psychol 2019;28:101-9.

23 Statistics Norway. Samordnet levekårsundersøkelse 2009 -Tverrsnitt. In: Tema: Arbeidsmiljø. Report in Norwegian. Oslo: Statistics Norway, 2010.

24 Orhede E. Nordic cooperation in research on the work environment. Scand J Work Environ Health 1994;20:65-6.
25 Sterud T, Hanvold TN. Effects of adverse social behaviour at the workplace on subsequent mental distress: a 3-year prospective study of the general working population in Norway. Int Arch Occup Environ Health 2020. doi:10.1007/s00420020-01581-y. [Epub ahead of print: 01 Nov 2020].

26 Dallner M. Validation of the General Nordic Questionnaire (QPSNordic) for psychological and social factors at work. [København. Nordisk Ministerråd, 2000.

27 Normann TM. Metodetester av spørsmål om arbeidsmiljø i levekårsundersøkelsen [Method tests of questions about working environment in the living conditions survey]. Oslo: Statistics Norway, 2009.

28 Norway S. International standard classification of occupations - ISCO-08 [Standard for yrkesklassifisering (STYRK-08)]. Oslo: Statistics Norway, 2011.

29 Natarajan S, Lipsitz SR, Rimm E. A simple method of determining confidence intervals for population attributable risk from complex surveys. Stat Med 2007;26:3229-39.

30 Bruzzi P, Green SB, Byar DP, et al. Estimating the population attributable risk for multiple risk factors using case-control data. Am J Epidemiol 1985;122:904-14.

31 Glymour MM, Weuve J, Berkman LF, et al. When is baseline adjustment useful in analyses of change? an example with education and cognitive change. Am J Epidemiol 2005; 162:267-78.

32 Senn SJ. Baseline adjustment in longitudinal studies. In: Armitage PC T, ed. Encyclopedia of biostatistics. 2 edn. Chichester: John Wiley, 2005: 294-7.

33 Siemiatycki J. A comparison of MAlL, telephone, and home interview strategies for household health surveys. Am J Public Health 1979;69:238-45.

34 Glambek M, Nielsen MB, Gjerstad J, et al. Gender differences in the relationship between workplace bullying and subjective back and neck pain: a two-wave study in a Norwegian probability sample. J Psychosom Res 2018;106:73-5. 